\title{
Biberiye ve Kekik Yağı İlavesinin Marine Edilen Gökkuşağı Alabalıklarının (Oncorhynchus Mykiss Walbaum 1972) Buzdolabında Depolanması üzerine Etkisi
}

\author{
Özlem Pelin Can*, Gonca Kaşıkçı
}

Cumhuriyet Üniversitesi, Mühendislik Fakültesi, Glda Mühendisliği Bölümü, 58140 Sivas, Türkiye

\begin{tabular}{l} 
M A K A L E B İ L G İ S İ \\
\hline Araştırma Makalesi \\
Geliş GG Ay Y11 \\
Kabul GG Ay Y1l
\end{tabular}

Anahtar Kelimeler:

Kekik

Biberiye

Alabalık

Marine

Yağ asidi kompozisyonu

Kimyasal kalite

$\frac{\text { *Sorumlu Yazar: }}{\text { E-mail: ozlempelincan@gmail.com }}$

\section{Ö Z E T}

Bu çalışmada, biberiye ve kekik yağı ekstraktları kullanılarak elde edilen alabalık (Oncorhynchus mykiss) marinatlarının depolanması sirasında meydana gelen kimyasal değişimler araştırılmış ve kullanılan bitkisel yağ ekstraktlarının ürünün yağ asidi kompozisyonu üzerine etkisi belirlenmeye çalıșılmıştır. Fileto haline getirilmiş balıklar üç farklı formülasyon kullanılarak (M grubu: $\% 4$ asetik asit-\%10 $\mathrm{NaCl}, \mathrm{B}$ grubu: $\% 4$ asetik asit- $\% 10 \mathrm{NaCl}-\% 0,1$ biberiye yağı ekstrakt1, $\mathrm{K}$ grubu: $\% 4$ asetik asit- $\% 10 \mathrm{NaCl}-\% 0,1$ kekik yağı ekstraktı) marine edilmiş, olgunlaşma aşamasından sonra vakum paketlenerek $+4^{\circ} \mathrm{C}$ ' deki buzdolabı koşullarında depolanmışlardır. Numunelerin 0. gün, 1., 2., 3., 4. ve 5. ayın sonunda kimyasal analizleri (pH, TBA, Peroksit Sayısı, TVB-N, Serbest yağ asitleri, yăg asitleri kompozisyonu) yapılmıştır. Deneysel örnekler TVB-N açısından değerlendirildiğinde depolamanın 3. ayında $\mathrm{K}$ grubu örneklerinde $14,12 \mathrm{mg} / 100 \mathrm{~g}, \mathrm{~B}$ grubu örneklerinde $19,2 \mathrm{mg} / 100 \mathrm{~g}$ ve $\mathrm{M}$ grubu örneklerinde ise $28,9 \mathrm{mg} / 100 \mathrm{~g}$ olarak tespit edilmiştir. $M$ grubu örnekleri TBA sayısı bakımından değerlendirildiğinde muhafazanın 3. ayında 5,84 mg MDA/ kg olup, diğer gruplar ile istatistiki fark önemli bulunmuştur. Kontrol grubu (M grubu) örneklerinin 4 ve 5. aylarda duyusal olarak bozulduğu için analizleri yapılamamıştır. Kontrol grubu ve $\mathrm{K}$ grubu örneklerinde marinasyon işlemi sonrasında, muhafaza periyodu boyunca EPA ve DHA değerlerinde düşüş şekillenmiş olup, istatistikî açıdan fark önemli bulunmuştur. Biberiye ilave edilen gruba ait örneklerin yağ asidi değerleri incelendiğinde, kaproik, miristik ve palmitik asit miktarları marinasyon işleminden sonra artmıştır ve fark istatistiki açıdan önemli bulunmuștur.

Turkish Journal of Agriculture - Food Science and Technology, 6(12): 1701-1707, 2018

The Effect of Rosemary and Thyme Oil Addition on the Rainbow Trout (Oncorhynchus mykiss Walbaum 1972) in Marinade Refrigerated Storage

\begin{tabular}{|c|c|}
\hline A R T I C LE I N F O & $\begin{array}{l}\text { A B S T R A C T } \\
\text { In this study, rosemary and thyme oil extracts obtained using trout (Oncorhynchusmykiss) }\end{array}$ \\
\hline Research Article & \multirow{12}{*}{$\begin{array}{l}\text { marinades of the chemical changes that occur during storage was investigated and effect } \\
\text { on fatty acid composition of vegetable oil extracts used in the product are determined. } \\
\text { Using three different formulations are made into fish fillets (M: } 4 \% \text { acetic acid- } 10 \% \\
\mathrm{NaCl}-0.1 \%, \mathrm{~B}: 4 \% \text { acetic acid- } 10 \% \mathrm{NaCl}-0.1 \% \text { of rosemary oil extract, } \mathrm{K}: 4 \% \text { acetic acid } \\
-10 \% \mathrm{NaCl}-\% 0.1 \text { thymol oil extract) was marinated, after the maturation stage vacuum } \\
\text { packaged at }+4^{\circ} \mathrm{C} \text { in the refrigerator conditions have been stored. Samples; } 0 \text { days } 1,2,3 \text {, } \\
4 \text { and } 5 \text { at the end of the month chemical analysis (pH, TBA, peroxide value, TVB-N, } \\
\text { free fatty acids, fatty acid composition) were conducted. Experimental samples were } \\
\text { evaluated in term of TVB- } \mathrm{N} \text { determined } \mathrm{M} \text { group samples } 28.9 \mathrm{mg} / 100 \mathrm{~g} \text {, B group } \\
\text { samples } 19.2 \mathrm{mg} / 100 \mathrm{~g} \text { and } \mathrm{K} \text { group samples } 14.12 \mathrm{mg} / 100 \mathrm{~g} \text { in the third month of } \\
\text { storage. When the samples of } \mathrm{M} \text { group were evaluated in terms of TBA number, it was } \\
5.84 \mathrm{mg} \mathrm{MDA} / \mathrm{kg} \text { at the } 3^{\text {rd }} \text { month of storage and statistical difference was found to be } \\
\text { significant with the other groups. The control group (M group) samples analysed were not } \\
\text { performed for sensory deterioration at } 4 \text { and } 5 \mathrm{months} \text {. After marination, the control } \\
\text { group and } \mathrm{K} \text { group samples decreased EPA and DHA during storage period, it was found } \\
\text { statistically significant difference. When the fatty acid values of the samples belonging to } \\
\text { the group containing rosemary were examined, caproic, myristic and palmitic acid } \\
\text { amounts increased after the marinate and difference statistically significant. }\end{array}$} \\
\hline Received DD Month Year & \\
\hline Accep & \\
\hline Keywords: & \\
\hline & \\
\hline Rosemary & \\
\hline Trout & \\
\hline Marinated & \\
\hline Fatty acid composition & \\
\hline Chemical qualit & \\
\hline *Corresponding Author: & \\
\hline E-mail: ozlempelincan@gmail.com & \\
\hline
\end{tabular}




\section{Giriş}

Balık eti, insan beslenmesinde önemli protein kaynakları arasında yer almaktadır. Ayrıca balık yağları yüksek miktarda doymamış yağ asitlerini içerir (Gökoğlu, 2002). Balık yağlarındaki çoklu doymamış yağ asitleri omega-3 şeklinde olup (Belitz ve Grosch, 1999), linoleik asit (C18:3), eikosapentaenoikasit (EPA) (C 20:5) ve dokosahekzaenoik asit (DHA) (C 22:6)' den oluşmaktadır (Spiller, 1996).

Ülkemizde balık taze olarak tüketiminin yanı sıra, dondurma veya dumanlama işlemine tabi tutulmaktadır. $\mathrm{Su}$ ürünlerindeki değişik işleme metotlarından biri marinat teknolojisidir. Marinatlar, balıkların ve kabukluların asetik asit ve tuz çözeltisinde 1sıl işlem uygulanmaksızın olgunlaştırılması ve değişik tatlar kazanması amacıyla şeker, baharatlar, salamura, sos ve sebzelerin de ilave edilerek cam şişe veya plastik kaplar içerisinde paketlendiği ürünlerdir (Gökoğlu, 2002; Gökoğlu ve ark., 2004; Çaklı, 2007).

Balık eti, içerdiği çoklu doymamış yağ asitlerinin çeşitliliği ve miktarının fazla oluşu ile diğer gıdalardan daha fazla oksidatif bozulmalara maruz kalmaktadır. Bunu önlemek amaciyla son yillarda tüketicilerinde tercih ettiği doğal antioksidanlar ilave edilerek üretimi ile ilgili çalışmalar hız kazanmıştır. Doğal antioksidanlardan olan esansiyel yağların doğal kaynaklı olmaları, kendine özgü lezzet ve aromaya sahip olmaları nedeniyle gida sektöründe kullanılabilecek önemli alternatif maddelerdir (Sherwin, 1990).

Doğal ürünlerden biberiye (Rosmarinus officinalis) ve kekik (Thymus vulgaris) uzun yıllardan beri doğal antioksidan olarak kullanılmakta olup aktif bileşenleri tespit edilmiştir (Nassu ve ark., 2003). Biberiyenin yapısında bulunan karnosik asit, karnosol ve rosmarinik asit gibi antioksidan etkili bileşikler ticari olarak kullanılmaktadırlar. Bir diğeri olan kekik gerek taze ette gerekse de et ürünlerinde yaygın olarak kullanılmaktadır. Kekiğin yapısında bulunan ve antioksidan etki gösteren bileşikler çeşitli fenolikler ve flavonoidlerdir (Önenç ve Açıkgöz, 2005; Yanishlieva ve ark., 2006). Bitki ekstraklarının oksitlenmeyi azaltıcı etkilerinin olduğu ve bu ekstraktların hamsi, sardalya ve kadife balığı etlerinde kullanıldığı bildirmektedir (Kılınç, 2003; Cadun ve ark., 2005; Olgunoğlu, 2007; Cadun ve ark., 2008). Bu çalışmada antioksidan özellikleri bulunan biberiye ve kekik yağı ilave edilerek marine edilmiş gökkuşağı alabalığının, bazı kimyasal kalite özellikleri ve yağ asidi kompozisyonu üzerindeki etkileri araştırılmıştır.

\section{Materyal ve Metot}

\section{Materyal}

Araştırma materyali olarak Cumhuriyet Üniversitesi Gürün Meslek Yüksekokulu Alabalık Çiftliğinde ağırlıkları yaklaşık 350-400 g olan gökkuşağı alabalığı temin edilmiştir ve soğuk zincir altında laboratuvara getirilmiştir. Araştırma 3 tekerrürlü olarak yapılmıştır. Her tekerrür için yaklaşık 40 adet balık kullanılmıştır. Araştırmada \%80'lik konsantrasyonda gida tipi asetik asit $\left(\mathrm{CH}_{3} \mathrm{COOH}\right)$ ve \%99,5 saflıkta kaya tuzu kullanılmıştır. Çalışmada kullanılan Biberiye (Herbalox ${ }^{\circledR}$ Seasoning) ve Kekik (Aquaresin ${ }^{\circledR}$ Thyme Code: 35-06-39) esansiyel yağları Frutarom firmasından temin edilmiştir. Ambalaj materyali olarak $15 \times 25 \mathrm{~cm}$ boyutlarında PA/PE'den (Poliamid/Polietilen) müteşekkil (3- seal bags GB 70) materyal $\left(\mathrm{O}_{2}\right.$ geçirgenliği $40 \mathrm{~cm}^{3} / \mathrm{m}^{2} /$ gün.atm. $23^{\circ} \mathrm{C} ; \mathrm{N}_{2}$ geçirgenliği $24 \mathrm{~cm}^{3} / \mathrm{m}^{2} /$ gün.atm $.23^{\circ} \mathrm{C} ; \mathrm{CO}_{2}$ geçirgenliği $145 \mathrm{~cm}^{3} / \mathrm{m}^{2} /$ gün. atm $.23^{\circ} \mathrm{C}$ ve su buharı geçirgenliği $<3$ $\mathrm{g} / \mathrm{m}^{2} /$ gün.atm. $23^{\circ} \mathrm{C}$ ) kullanılmıştır.

\section{Metot}

Materyalin hazırlanması: Alabalıklar baş, iç organ ve kılçıklarından ayrıldıktan sonra soğuk su ile yıkanmıştır. Elde edilen filetolar kan ve mukozalarından uzaklaştırılmak amacıyla \%10'luk tuz çözeltisi içinde 30 dakika kadar bekletilmiştir. Ardından suları süzülene kadar süzgeçte bekletilmiştir.

Marinasyon işlemi: Marinasyon işlemi, üç farklı formülasyon kullanılarak gerçekleştirilmiştir. Birinci formülasyonda; $\% 4$ asetik asit, $\% 10 \mathrm{NaCl}, \% 0,1$ kekik ekstraktı (Grup K), ikinci formülasyonda; \%4 asetik asit, $\% 10 \mathrm{NaCl}, \% 0,1$ biberiye ekstraktı (Grup B), üçüncü formülasyonda ise $\% 4$ asetik asit, $\% 10 \mathrm{NaCl}$ (Grup M) kullanılmıştır. Salamuralar hazırlandıktan sonra 1:2 balık: salamura oranında plastik bidonlara yerleştirilmiştir. Daha sonra bidonlar, marinasyon işemi gerçekleşene kadar $+4^{\circ} \mathrm{C}$ ' de bekletilmiştir. Filetolar duyusal açıdan 24 saatte bir kontrol edilmiş ve 7. gün sonunda olgunlaştırma işlemi sonlandırılmıştır.

Vakum paketleme ve depolama: Olgunlaştırma sonrasında filetolar salamuradan çıkarılarak suları tamamen süzdürülmüştür. Yaklaşık ağırlıkları $100 \pm 5 \mathrm{~g}$ ile $130 \pm 5 \mathrm{~g}$ arasinda olan filetolar polietilen torbalara yerleştirilmiş ve vakum paketleme (TURBOVAC, Bosch) yapılmış ve örnekler $+4{ }^{\circ} \mathrm{C}$ 'de muhafazaya alınmıştır. Deneysel örnekler marinasyon işleminin tamamlandığı 0 . gün, 1.,2., 3., 4. ve 5. aylarda kimyasal analizler ve yağ asidi kompozisyonları açısından incelenmiştir.

\section{Analiz Yöntemleri}

Kimyasal analizler: Toplam uçucu bazik azot (TVBN) tayini, Varlık ve ark. (1993a)'nın uyguladığı yöntem esas alınarak, distilasyon işlemiyle yapılmıştır. Tiyobarbitürik Asit (TBA) Sayısı Tarladgis ve ark. (1960)'nın uyguladığı yönteme göre yapılmıştır. Peroksit sayısı tayini modifiye edilmiş Wheeler yöntemine göre yapılmıştır (Varlık, 1993a). Serbest yağ asitleri tayini ise titrasyon metodu ile AOAS' a göre yapılmıştır.

Yağ asidi kompozisyonutayini: Yağ asitleri tayini gaz kromotografisi yönteml ile yaptırılmıştır. Eksrakte edilmiş lipitten, yağ asidi metil esterleri, methanol ve n- hexan içinde $2 \mathrm{M}$ ' lik $\mathrm{KOH}$ oluşmuş transmetillendirme yöntemi ile hazırlanmıştır. $10 \mathrm{mg}$ eksrakte edilmiş yağ örneği üzerine $4 \mathrm{ml} 2 \mathrm{M}^{\prime} \mathrm{l} \mathrm{k} \mathrm{KOH}$ oluşan $2 \mathrm{ml}$ hexan ilave edilmiştir. Daha sonra oda sıcaklığında 2 dakika vortekste karıştırılmış ve 4000 rpm'de 10 dakika süreyle santürfüj edilmiş ve hexan tabakası GC' de analiz için alınmıştır. Yağ asitleri kompozisyonu alev iyonizasyon dedektörlü (FID) ve $30 \mathrm{~m} \times 0,32 \mathrm{~mm}$ IDx0.25 $\mu \mathrm{m}$ film kalınlığında SGE kolonlu otomatik örneklemeli (Perkin Emler, USA) GC (Gaz kromatografisi) kullanılarak gerçekleştirilmiştir. Enjektör ve detektör sicaklıkları sirasıyla önce $220^{\circ} \mathrm{C}$ sonra $280^{\circ} \mathrm{C}^{\prime}$ ye ayarlanmıştır. Bu esnada firın sıcaklığ 5 dakikada $140^{\circ} \mathrm{C}^{\prime} \mathrm{de}$ tutulmuştur. Sonrasında $200^{\circ} \mathrm{C}^{\prime} \mathrm{ye}$ 
kadar, her dakika $4^{\circ} \mathrm{C}$ arttırılarak, $200^{\circ} \mathrm{C}$ 'den $220^{\circ} \mathrm{C}^{\prime}$ ye de her dakika $1^{\circ} \mathrm{C}$ arttırılarak getirilmiştir. Örnek miktarı 1 ml olup, taşıyıcı gazı kontrolü 16ps' de olması sağlanmıştır. Enjeksiyon uygulaması 1:100 oranında gerçekleştirilmiştir. Yağ asitleri standart 37 bileşenden oluşan FAME karışımının gelme zamanlarına bağlı olarak karşılaştırılmasıyla tanımlanmıştır.

\section{Istatistiksel Analizler}

$\mathrm{Bu}$ araştırmada, verilerin değerlendirilmesinde varyans analizi (ANOVA) testinden yararlanılmıştır. Ortalamaların ayrıştırılması, Fisher'in Least Significance Difference (LSD) metodu kullanılarak yapılmıştır. İstatistiki analizlerde 0,05 'lik önem düzeyi $(\mathrm{P}<0,05)$ olarak dikkate alınmıştır. Bütün analizler Statistical Analysis System (SAS) programından yararlanılarak gerçekleştirilmiştir (SAS, 1999).

\section{Bulgular ve Tartışma}

Marinasyon öncesi, alabalık filetolarına uygulanan analizlerin sonuçları Tablo 1'de verilmiştir. İşlem görmemiş filetolara ait TVB-N değeri, TBA sayısı, peroksit sayısı, serbest yağ asitleri miktarı ve $\mathrm{pH}$ değeri sirasiyla 9,42 mg/100g, 0,31 mg MDA/ kg, 1,07 milimol $\mathrm{O}_{2} / \mathrm{kg}$ ve 6,48 olup, bu değerlerin tümü tüketilebilirlik sınırlarının altında yer almaktadır. Can ve Patır (2012)'nın yapmış olduğu bir çalışmada işlem görmemiş alabalık filetolarındaki TVB-N değeri 7,5 mg/100 g, TBA sayısı ise $0,4 \mathrm{mg} \mathrm{MDA} / \mathrm{kg}$ olarak bildirilmiştir. Her iki değer kıyaslandığında mevcut çalışmaya ait bulgular ile uyum içerinde olduğu görülmektedir.

Balık ve su ürünlerinin tazeliğinin belirlenmesinde kimyasal yöntemlerden biri olan TVB-N tayini, önemli bir parametredir. Üç ayrı formülasyonla marine edilmiş alabalıklara ait TVB-N değerleri Tablo 2'de verilmiştir. Muhafazanın 0 . gününde $\mathrm{B}$ ve $\mathrm{K}$ grubu örneklerdeki TVB-N değerinde düşüş tespit edilmiştir, ancak grupların TVB-N değerleri arasında önemli bir fark gözlenmemiştir $(\mathrm{P}>0,05)$. K grubu örneklerinde depolamanın 1. ayı ve sonraki depolama sürelerinde TVB-N değerlerinin diğer gruplardan istatistiki olarak önemli düzeyde daha düşük olduğu gözlenmiştir. Depolamanın1. ayında $\mathrm{K}$ grubu örneklerinin TVB-N değeri $6,15 \mathrm{mg} / 100 \mathrm{~g}$ iken ve B grubu örneklerde TVB-N değerleri sırasıyla 9,33 ve 8,92 $\mathrm{mg} / 100 \mathrm{~g}$ bulunmuştur. Kontrol grubu örneklerinde TVB$\mathrm{N}$ değeri muhafaza süresince artarak 3 . ayda $28,9 \mathrm{mg} / 100$ g değerine ulaşmıştır (Tablo 2). Olgunoğlu (2007), marine edilmiş hamsinin duyusal, kimyasal ve mikrobiyolojik kriterlerini araştırdığ $11,90 \mathrm{mg} / 100 \mathrm{~g}$ 'lık bir değerle "çok iyi" durumda olan ürünün TVB-N değerinin 7. aya kadar sürekli yükselerek ortalama $16,91 \mathrm{mg} / 100 \mathrm{~g}$ değerine ulaştığını bildirmiştir. $\mathrm{Bu}$ durumun, farklı balık türlerinden, hijyen farklılığından, depolama koşullarındaki değişiklikten ve kullanılan yöntemin farklı olduğundan kaynaklandığı düşünülmektedir. Araştırma sonucunda elde edilen aylık TVB-N değerleri arasında yapılan istatistiksel karşılaştırmada depolama süresine bağlı değişimlerin önemli olduğu saptanmıştır. Eke (2007), farklı balık türlerinden marinat yapımı ve kalitesinin belirlenmesi isimli çalışmasında; 0. gün palamut, hamsi ve zargana balıklarının ortalama TVB-N değerlerini sırası ile $12,13 \pm 0,47 \mathrm{mg} / 100 \mathrm{~g}, 7,47 \pm 0,47 \mathrm{mg} / 100 \mathrm{~g}$ ve $9,33 \pm 1,87$ $\mathrm{mg} / 100 \mathrm{~g}$ olarak ölçmüştür. TVB-N değerlerinin depolamaya bağlı olarak artış göstermiş olduğunu ve depolama sonunda palamut marinatında 17,63 $\pm 0,77$ $\mathrm{mg} / 100 \mathrm{~g}$, hamsi marinatinda $18,67 \pm 0,47 \mathrm{mg} / 100 \mathrm{~g}$ ve zargana marinatında $16,80 \pm 0,81 \mathrm{mg} / 100 \mathrm{~g}$ olarak tespit edildiğini bildirmiştir.

TBA değeri lipit oksidasyonunu tespit etmede önemli bir metottur. Çok iyi materyalde TBA sayısı 3'den az olmalı, iyi bir materyalde ise 5'ten fazla olmamalıdır. Tüketilebilirlik sınır değeri 7-8 arasındadır (Connell, 1980). Üç ayrı formülasyonla marine edilmiş alabalıklara ait TBA değerleri Tablo 2'de verilmiştir. Taze örnekte ortalama $0,31 \mathrm{mg}$ malonaldehid $/ \mathrm{kg}$ değerinde bulunan TBA sayısı (Tablo 1), olgunlaşma sonunda $\mathrm{M}$ grubu örneklerinde $0,42 \mathrm{mg}$ malonaldehid $/ \mathrm{kg}, \mathrm{B}$ grubu örneklerinde $0,49 \mathrm{mg}$ malonaldehid $/ \mathrm{kg}$ ve $\mathrm{K}$ grubu örneklerinde $0,4 \mathrm{mg}$ malonaldehid $/ \mathrm{kg}$ olup, 3. ayda sirasiyla 5,84 $\mathrm{mg}$ malonaldehid/kg, 1,14 mg malonaldehid/kg ve $0,19 \mathrm{mg}$ malonaldehid/kg olarak tespit edilmiştir. Grup içi günler değerlendirildiğinde $\mathrm{K}$ ve $\mathrm{B}$ grubuna ait örneklerdeki fark önemsiz $(\mathrm{P}>0,05)$ iken $\mathrm{M}$ grubu örneklerindeki fark önemli $(\mathrm{P}<0,05)$ olarak bulunmuştur. $\mathrm{Bu}$ durumun marinasyon işleminde kullanılan esansiyel yağlardan kaynaklandığı düşünülmektedir. Yine $M$ grubu örnekleri 3. Ay sonuda TBA sayısı bakımından tüketilebilirlik sınırı içerinde yer almıştır, fakat örnekler duyusal açıdan ve diğer kimyasal parametreler açısından göz önünde bulundurulduğundan sonraki aylar TBA sayısı bakımından incelenmemiştir. Muhafaza süresi sonunda en düşük değere $\mathrm{K}$ grubu örneklerinde $1,88 \pm 0,08 \mathrm{mg}$ malonaldehid $/ \mathrm{kg}$ olarak saptanmıştır ancak $\mathrm{K}$ grubu ve $\mathrm{B}$ grubu örnekleri istatistiki açıdan önemli bulunmamıştır $(\mathrm{P}>0,05)$. Özden ve Erkan (2006), tarafından yapılan marine edilmiş gökkuşağı alabalığının raf ömrü üzerine farklı paketleme yöntemlerinin etkisi isimli çalışmada, TBA değerini depolama periyodu başında marine edilmiş balıkta $2,8 \mathrm{mg}$ malonaldehid/kg olarak belirlemişlerdir. İki farklı yöntemle paketledikleri hamsi marinatlarındaki TBA değerlerinin zamana bağlı olarak artış gösterdiğini ve depolamanın 90. gününde TBA değerlerini vakumda paketlenen ürünlerde $9,5 \mathrm{mg}$ malonaldehid/ $\mathrm{kg}$ ve yağda paketlenen örneklerde 10,26 mg malonaldehid/ $\mathrm{kg}$ olarak ölçerek tüketilebilirlik sınırını aştıklarını belirlemişlerdir.

Tablo 1 İşlenmemiş Alabalık filetolarına ait analiz bulguları Table 1 The analysis finding untreated rainbow trout fillets

\begin{tabular}{l|l}
\hline \multicolumn{1}{c|}{ Yapılan Analizler } & \multicolumn{1}{c}{ Analiz Bulgular1 } \\
\hline TVB-N & $9,42 \pm 0,17(\mathrm{mg} / 100 \mathrm{~g})$ \\
TBA & $0,31 \pm 0,02(\mathrm{mg}$ malonaldehid $/ \mathrm{kg})$ \\
Peroksit Sayısı & $1,07 \pm 0,19\left(\mathrm{milimol} \mathrm{O} \mathrm{O}_{2} / \mathrm{kg}\right)$ \\
Serbest Yağ Asitleri & $0,63 \pm 0,07(\%$ oleik asit $)$ \\
\hline
\end{tabular}


Elde edilen TBA değeri sonuçları ile duyusal analiz sonuçları arasında iyi bir korelasyon olduğunu ve depolama süresince TBA değerinde paketleme materyalleri arasında önemli bir değişimin olmadığını belirtmişlerdir. Cadun ve ark. (2008), biberiye ekstraktı ilave edilmiş pembe karideslerinin raf ömrü sürelerini belirlemek üzere yaptıkları çalışmada, biberiye ekstraktının TBA değeri üzerine etki ettiği ve depolama başlangıcında kontrol grubunda TBA değerinin $0,9 \pm 0,04$ $\mathrm{mg}$ malonaldehit $/ \mathrm{kg}$, ekstrakt ilaveli grupta ise $0,4 \pm 0,10$ $\mathrm{mg}$ malonaldehit/kg olduğu belirlenmiştir. Depolamaya bağlı olarak artış gösterdiği bildirilen TBA değeri depolamanın 75. gününde kontrol grubunda $6,6 \pm 0,4 \mathrm{mg}$ malonaldehit/kg ve ekstrakt ilaveli grupta $2,4 \pm 0,7 \mathrm{mg}$ malonaldehit/kg olarak tespit edilmiştir. Sonuç olarak biberiye ekstraktının lipit oksidasyonunu engelleyici yönde etkisinin olduğunu bildirmiştir. Çetinkaya (2008), gümüş balığından marinat yapımı ve bazı besinsel özelliklerinin belirlenmesi üzerine yaptığı çalışmasında, iki farklı formülasyon (\%10 tuz \%2-\%3 sirke) kullanmıştır. Yaptı̆̆ 1 marinatlardaki TBA değerlerinin depolama başlangıcında taze örnekte 0,52 , marinasyon işlemi sonrasında $\% 2$ sirkeli marinatlarda 4,68, \%3 sirkeli marinatlarda 4,27 olarak tespit etmiştir. TBA değerinin depolama süresince inişli çıkışlı bir durum sergilediğini bildiren araştırmacı depolamanın 120. gününde TBA değerini \%2 sirkeli grupta 4,00 ve \%3 sirkeli grupta 4,52 olarak saptamıştır. Araştırmacı, çalışmanın sonunda elde ettiği TBA değerlerinin tüketilebilirlik sınırları içerisinde olduğunu bildirmiştir.

Doymamış yağ asitlerinin oksidasyonunda şekillenen ilk ürünlerden birisi peroksitlerdir. $\mathrm{Bu}$ bakımdan acılaşmanın başlangıç safhalarında oluşan peroksitlerin saptanması çoğu zaman kalite göstergesi olarak kullanılmaktadır. Yağlarda oksidasyonun bir göstergesi olan peroksit sayısı, yağlarda bulunan aktif oksijen miktarının bir ölçüsü olup, $1 \mathrm{~kg}$ yağda bulunan peroksit oksijeninin miliekivalan olarak eşdeğeridir (Yapar ve Erdöl, 1999). Deneysel örneklere ait peroksit değerleri Tablo 2'de verilmiştir. Çiğ filetoda peroksit sayısı
$1,07 \pm 0,19$ milimol $\mathrm{O}_{2} / \mathrm{kg}$ olarak belirlenmiştir. Marinasyon işlemi sonunda bu değer $1,13 \pm 0,13-1,7 \pm 0,39$ milimol $\mathrm{O}_{2} / \mathrm{kg}$ arasında tespit edilmiştir. Kontrol grubu örneklerde 0 . günde peroksit sayısı $1,13 \pm 0,13$ milimol $\mathrm{O}_{2} / \mathrm{kg}$ olarak saptanmıştır. Muhafazanın ilerlemesiyle birlikte düzenli olarak artış gösteren peroksit sayısı, 2 . ayda $9,74 \pm 0,72$ milimol $\mathrm{O}_{2} / \mathrm{kg}$ 'a ulaşmıştır. 0 . gün ile 1 ., 3. ve 5. aylar arasındaki farklılık önemli bulunmuştur $(\mathrm{P}<0,05)$. Peroksit sayısı, biberiye yağı uygulanmış $\mathrm{B}$ grubu örneklerde 0 . günde $1,5 \pm 0,11 \mathrm{milimol}_{2} / \mathrm{kg}$ iken 4. ayda $6,42 \pm 1,19$ milimol $\mathrm{O}_{2} / \mathrm{kg}$ değerine ulaşmıştır. 0 . gün ile 4. ve 5. aylar arasındaki farklılık istatistiki olarak önemli bulunmuştur $(\mathrm{P}<0,05)$. Kekik yağı uygulanmış $\mathrm{K}$ grubu örneklerinde 2. aya kadar önemli farklılıklar kaydedilmemiştir $(\mathrm{P}>0,05)$. Bu grupta en yüksek peroksit değeri 5. ayda $\left(7,74 \pm 2,59\right.$ milimol $\left.\mathrm{O}_{2} / \mathrm{kg}\right)$ saptanmıştır. Özden ve Erkan (2006), alabalık marinatları ile yaptıkları çalışmada peroksit değerini taze örnekte $3,9 \mathrm{mmol} \mathrm{O}_{2} / \mathrm{kg}$ olarak belirlemişlerdir. Vakum paketlenerek $+4^{\circ} \mathrm{C}$ 'de depolanan alabalık marinatlarının 90. günde 10,85 mmol $\mathrm{O}_{2} / \mathrm{kg}$, yă içerisinde paketlenen marinat grubunun 10,23 mmol $\mathrm{O}_{2} / \mathrm{kg}$ değerine ulaşarak sınır değeri aştıklarını bildirmişlerdir. Depolama sonunda paketleme materyalleri arasında peroksit değeri bakımından önemli bir fark olmadığı belirtilmiştir. Özoğul ve ark., (2009), kadife balığından marinat yapımı ve buzdolabı koşullarında depolanması sırasında meydana gelen kalite değişimlerini inceledikleri araştırmalarında, depolama başlangıcında peroksit değerini $8,4 \pm 2,2 \mathrm{meqO}_{2} / \mathrm{kg}$ olarak tespit etmişlerdir. Depolamanın 120. gününde $28,85 \pm 3,2$ $\mathrm{meqO}_{2} / \mathrm{kg}$ değerine yükselip daha sonra depolamanın 180 . gününde $19,6 \pm 2,5 \quad$ meqO$_{2} / \mathrm{kg}$ değerine indiğini bildirmişlerdir.

Serbest yağ asitleri (SYA) trigliserit ve fosfolipitlerin lipolizi ile şekillenir. Gıdanın bileşiminde serbest yağ asidi miktarının artması oksidasyonu hılandıran etmenlerden birisidir. Lipit oksidasyonu da muhafaza ömrünü sınırlandıran en önemli faktörlerden birisidir. İşlem görmemiş filetoda serbest yağ asidi miktarı $\% 0,63 \pm 0,07$ olarak belirlenmiştir (Tablo 1).

Tablo 2 Deneysel fileto örneklerinin muhafazası sırasında tespit edilen kimyasal analiz değerleri Table 2 Chemical analysis values determined during storage of experimental fillet samples

\begin{tabular}{|c|c|c|c|c|c|c|c|}
\hline \multirow[b]{2}{*}{ Analiz } & \multirow[b]{2}{*}{ Gruplar } & \multicolumn{6}{|c|}{ Muhafaza süresi (ay) } \\
\hline & & $\begin{array}{c}0 \\
(\mathrm{O} \pm \mathrm{S})\end{array}$ & $\begin{array}{c}1 \\
(\mathrm{O} \pm \mathrm{S})\end{array}$ & $\begin{array}{c}2 \\
(\mathrm{O} \pm \mathrm{S})\end{array}$ & $\begin{array}{c}3 \\
(\mathrm{O} \pm \mathrm{S})\end{array}$ & $\begin{array}{c}4 \\
(\mathrm{O} \pm \mathrm{S})\end{array}$ & $\begin{array}{c}5 \\
(\mathrm{O} \pm \mathrm{S})\end{array}$ \\
\hline \multirow{3}{*}{$\begin{array}{l}\text { TVB } \\
\mathrm{mg} / 100 \mathrm{~g}\end{array}$} & M & $9,33 \pm 0,74^{\mathrm{a}, \mathrm{x}}$ & $10,24 \pm 1,2^{\mathrm{a}, \mathrm{x}}$ & $19,43 \pm 1,6^{\text {a,y }}$ & $28,9 \pm 2,3^{\mathrm{a}, \mathrm{z}}$ & $*$ & $*$ \\
\hline & $\mathrm{K}$ & $7,58 \pm 0,56^{\mathrm{a}, \mathrm{y}}$ & $6,15 \pm 1,18^{\mathrm{b}, \mathrm{y}}$ & $7,23 \pm 2,16^{\mathrm{b}, \mathrm{y}}$ & $14,12 \pm 1,86^{\mathrm{b}, \mathrm{z}}$ & $18,02 \pm 2,13^{\mathrm{a}, \mathrm{z}}$ & $20,02 \pm 3,1^{\mathrm{b}, \mathrm{z}}$ \\
\hline & $\mathrm{B}$ & $8,92 \pm 0,8^{\mathrm{a}, \mathrm{x}}$ & $9,29 \pm 1,19^{a, x}$ & $17,45 \pm 2,43^{\mathrm{a}, \mathrm{y}}$ & $19,2 \pm 2,6^{\mathrm{ab}, \mathrm{y}}$ & $22,4 \pm 2,19^{\mathrm{a}, \mathrm{z}}$ & $28,8 \pm 3,11^{\mathrm{a}, \mathrm{z}}$ \\
\hline \multirow{3}{*}{$\begin{array}{l}\text { TBA } \\
\mathrm{mgMDA} / \mathrm{kg}\end{array}$} & $\mathrm{M}$ & $0,42 \pm 0,36^{\mathrm{a}, \mathrm{x}}$ & $2,6 \pm 0,05^{\mathrm{a}, \mathrm{y}}$ & $4,8 \pm 0,08^{\mathrm{a}, \mathrm{y}}$ & $5,84 \pm 0,06^{\mathrm{a}, \mathrm{z}}$ & $*$ & $*$ \\
\hline & $\mathrm{K}$ & $0,4 \pm 0,25^{\mathrm{a}, \mathrm{y}}$ & $0,7 \pm 0,04^{\mathrm{b}, \mathrm{y}}$ & $0,7 \pm 0,06^{\mathrm{b}, \mathrm{y}}$ & $0,9 \pm 0,02^{\mathrm{b}, \mathrm{y}}$ & $1,3 \pm 0,02^{\mathrm{a}, \mathrm{z}}$ & $1,88 \pm 0,08^{\mathrm{a}, \mathrm{z}}$ \\
\hline & $\mathrm{B}$ & $0,49 \pm 0,43^{\text {a,y }}$ & $0,6 \pm 0,17^{\text {b,y }}$ & $0,8 \pm 0,21^{\mathrm{b}, \mathrm{y}}$ & $1,14 \pm 0,06^{\mathrm{b}, \mathrm{zy}}$ & $1,96 \pm 0,04^{\mathrm{a}, \mathrm{z}}$ & $2,03 \pm 0,09^{\mathrm{a}, \mathrm{z}}$ \\
\hline PD & M & $1,13 \pm 0,13^{\mathrm{a}, \mathrm{k}}$ & $3,84 \pm 0,46^{\mathrm{a}, \mathrm{x}}$ & $9,74 \pm 0,72^{\mathrm{a}, \mathrm{y}}$ & $15,6 \pm 0,53^{\mathrm{a}, \mathrm{z}}$ & $*$ & $*$ \\
\hline milimol & $\mathrm{K}$ & $1,7 \pm 0,21^{\mathrm{a}, \mathrm{k}}$ & $2,85 \pm 0,33^{\mathrm{a}, \mathrm{x}}$ & $2,94 \pm 0,46^{\mathrm{c}, \mathrm{x}}$ & $4,62 \pm 0,28^{\mathrm{b}, \mathrm{y}}$ & $5,85 \pm 1,17^{\mathrm{a}, \mathrm{y}}$ & $7,74 \pm 2,59^{\mathrm{a}, \mathrm{z}}$ \\
\hline $\mathrm{O}_{2} / \mathrm{kg}$ & $\mathrm{B}$ & $1,5 \pm 0,11^{\mathrm{a}, \mathrm{k}}$ & $3,0 \pm 0,42^{\mathrm{a}, \mathrm{y}}$ & $4,01 \pm 0,36^{\mathrm{b}, \mathrm{y}}$ & $4,31 \pm 0,17^{\mathrm{b}, \mathrm{y}}$ & $6,42 \pm 1,19^{\mathrm{a}, \mathrm{z}}$ & $7,75 \pm 0,98^{\mathrm{a}, \mathrm{z}}$ \\
\hline \multirow{3}{*}{$\begin{array}{l}\text { SYA } \\
\% \text { oleik asit }\end{array}$} & $\mathrm{M}$ & $0,72 \pm 0,04^{\mathrm{a}, \mathrm{k}}$ & $2,7 \pm 0,02^{\mathrm{a}, \mathrm{y}}$ & $4,72 \pm 0,04^{\mathrm{a}, \mathrm{x}}$ & $7,33 \pm 0,14^{\mathrm{a}, \mathrm{z}}$ & $*$ & $*$ \\
\hline & $\mathrm{K}$ & $0,61 \pm 0,04^{\mathrm{a}, \mathrm{k}}$ & $1,14 \pm 0,02^{\mathrm{b}, \mathrm{y}}$ & $1,05 \pm 0,16^{\mathrm{b}, \mathrm{y}}$ & $2,73 \pm 0,03^{\mathrm{b}, \mathrm{z}}$ & $2,96 \pm 0,04^{\mathrm{a}, \mathrm{z}}$ & $3,11 \pm 0,07^{\mathrm{a}, \mathrm{z}}$ \\
\hline & B & $0,70 \pm 0,1^{\mathrm{a}, \mathrm{k}}$ & $0,97 \pm 0,06^{\mathrm{b}, \mathrm{y}}$ & $1,22 \pm 0,04^{\mathrm{b}, \mathrm{y}}$ & $2,02 \pm 0,22^{\mathrm{b}, \mathrm{zy}}$ & $2,56 \pm 0,5^{\mathrm{a}, \mathrm{z}}$ & $3,82 \pm 0,03^{\mathrm{a}, \mathrm{z}}$ \\
\hline
\end{tabular}

z, y, x: Aynı sütunda, farklı harfleri taşıyan ortalamalar arasında fark istatistik olarak önemlidir $(\mathrm{P}<0,05)$. a,b: Aynı satırda, farklı harfleri taşıyan ortalamalar arasında fark istatistik olarak önemlidir $(\mathrm{P}<0,05)$. *: Analiz yapılmadı. n:3. 0: Marinasyon işleminin tamamlandığı ve filetoların paketlendiği gün. 
Tablo 3 Kontrol grubuna ait fileto örneklerinin muhafazası sırasında tespit edilen yăg asidi değerleri

Table 3 Fatty acid values detected during storage of fillet samples of control group

\begin{tabular}{|c|c|c|c|c|c|}
\hline \multirow{2}{*}{ Yağ asitleri } & \multicolumn{5}{|c|}{ Muhafaza süresi (Ay) } \\
\hline & MÖ & $0 *$ & 1 & 2 & 3 \\
\hline \multicolumn{6}{|l|}{ SFA } \\
\hline C6:0 Kaproik asit & 0,04 & 0,09 & 0,11 & 0,08 & 0,10 \\
\hline C12:0 Laurik asit & 0,14 & 0,23 & 0,18 & 0,16 & 0,14 \\
\hline C14:0 Miristik asit & $3,81^{\mathrm{b}}$ & $4,3^{\mathrm{a}}$ & $3,8^{\mathrm{b}}$ & $4,73^{\mathrm{a}}$ & $3,72^{b}$ \\
\hline C16:0 Palmitik asit & $17,29^{\mathrm{a}}$ & $16,77^{\mathrm{b}}$ & $16,71^{\mathrm{b}}$ & $16,09^{\mathrm{b}}$ & $16,3^{\mathrm{b}}$ \\
\hline C18: 0 Stearik asit & 5,53 & 5,35 & 5,42 & 5,86 & 5,93 \\
\hline$\sum$ SFA & $32,41^{\mathrm{a}}$ & $31,13^{\mathrm{b}}$ & $30,29^{c}$ & $30,56^{\mathrm{c}}$ & $31,41^{\mathrm{b}}$ \\
\hline \multicolumn{6}{|l|}{ UFAMUFA } \\
\hline C16:1 ( $\omega-6)$ Palmiteolik asit & 0,65 & 0,59 & 0,53 & 0,61 & 0,55 \\
\hline C18:1 Oleik asit & $33,92^{\mathrm{a}}$ & $28,45^{\mathrm{b}}$ & $28,31^{\mathrm{b}}$ & $28,19^{\mathrm{b}}$ & $27,91^{\mathrm{c}}$ \\
\hline$\sum$ MUFA & $31,2^{\mathrm{a}}$ & $30,3^{\mathrm{a}}$ & $29,57^{\mathrm{b}}$ & $30,16^{\mathrm{a}}$ & $30,21^{\mathrm{a}}$ \\
\hline \multicolumn{6}{|l|}{ PUFA } \\
\hline c18:2 ( $\omega-6)$ Linoleik asit & 10,42 & 10,56 & 10,21 & 10,33 & 10,41 \\
\hline C18:3 $(\omega-6)$ Linolenik asit & 2,95 & 2,21 & 2,19 & 2,09 & 2,11 \\
\hline C20:5 ( $\omega-3)$ Eikosapentaenoik asit (EPA) & $3,41^{\mathrm{a}}$ & $2,11^{b}$ & $2,26^{\mathrm{b}}$ & $1,19^{\mathrm{c}}$ & $1,13^{\mathrm{c}}$ \\
\hline $\mathrm{C} 20: 4(\omega-6)$ Araşidonik asit & $1,33^{\mathrm{a}}$ & $0,86^{\mathrm{b}}$ & $0,71^{\mathrm{b}}$ & $0,53^{\mathrm{c}}$ & $0,57^{\mathrm{c}}$ \\
\hline C22:6 $(\omega-3)$ Dokosaheksanoik asit (DHA) & $9,17^{b}$ & $12,53^{\mathrm{a}}$ & $10,21^{\mathrm{b}}$ & $8,76^{\mathrm{bc}}$ & $7,63^{\mathrm{c}}$ \\
\hline$\sum$ PUFA & $27,3^{\mathrm{a}}$ & $22,11^{\mathrm{b}}$ & $23,56^{\mathrm{b}}$ & $23,31^{\mathrm{b}}$ & $22,96^{b}$ \\
\hline$\sum$ UFA & $59,5^{\mathrm{a}}$ & $52,41^{\mathrm{c}}$ & $53,1^{\mathrm{b}}$ & $53,47^{\mathrm{b}}$ & $53,17^{b}$ \\
\hline SFA/UFA & 0,54 & 0,59 & 0,57 & 0,57 & 0,59 \\
\hline
\end{tabular}

MÖ: Marinasyon öncesi, SFA: Doymuş yağ asitleri, UFA: Doymamış yağ asitleri, MUFA: Tekli doymamış yağ asitleri, PUFA: Çoklu doymamış yağ asitleri, a,b, c: Aynı satırda, farklı harfleri taşıyan ortalamalar arasında fark istatistik olarak önemlidir (P<0,05). 0: Marinasyon işleminin tamamlandığı ve filetoların paketlendiği gün

Tablo 4 Biberiye ekstraktı ilave edilen gruba (B grubu) ait örneklerin muhafazası sırasında tespit edilen yağ asidi değerleri Table 4 Fatty acid values detected during storage of fillet samples of rosemary oil with group

\begin{tabular}{|c|c|c|c|c|c|c|c|}
\hline \multirow{2}{*}{ Yağ asitleri } & \multicolumn{7}{|c|}{ Muhafaza süresi (Ay) } \\
\hline & MÖ & $0 *$ & 1 & 2 & 3 & 4 & 5 \\
\hline \multicolumn{8}{|l|}{ SFA } \\
\hline C6:0 Kaproik asit & $0,04^{\mathrm{c}}$ & $0,13^{\mathrm{b}}$ & $0,19^{b}$ & $0,24^{b}$ & $0,33^{\mathrm{a}}$ & $0,28^{\mathrm{a}}$ & $0,31^{\mathrm{a}}$ \\
\hline C12:0 Laurik asit & 0,14 & 0,11 & 0,18 & 0,13 & 0,15 & 0,11 & 0,12 \\
\hline C14:0 Miristik asit & $3,81^{\mathrm{b}}$ & $3,73^{b}$ & $4,2^{\mathrm{a}}$ & $4,55^{\mathrm{a}}$ & $4,13^{\mathrm{a}}$ & $4,51^{\mathrm{a}}$ & $4,49^{\mathrm{a}}$ \\
\hline C16:0 Palmitik asit & $17,29^{\mathrm{b}}$ & $17,27^{\mathrm{b}}$ & $18,19^{\mathrm{b}}$ & $20,33^{\mathrm{ab}}$ & $21,56^{\mathrm{a}}$ & $23,32^{\mathrm{a}}$ & $22,56^{\mathrm{a}}$ \\
\hline C18: 0 Stearik asit & $5,53^{\mathrm{b}}$ & $5,61^{\mathrm{b}}$ & $6,63^{\mathrm{a}}$ & $6,42^{\mathrm{a}}$ & $5,57^{\mathrm{b}}$ & $5,83^{\mathrm{b}}$ & $5,61^{b}$ \\
\hline$\sum$ SFA & $32,41^{\mathrm{a}}$ & $32,3^{\mathrm{a}}$ & $31,67^{\mathrm{b}}$ & $31,93^{\mathrm{b}}$ & $32,56^{\mathrm{a}}$ & $31,77^{\mathrm{b}}$ & $31,79^{\mathrm{b}}$ \\
\hline \multicolumn{8}{|l|}{ UFA MUFA } \\
\hline C16:1 $(\omega-6)$ Palmiteolik asit & $0,65^{\mathrm{a}}$ & $0,51^{\mathrm{b}}$ & $0,54^{\mathrm{b}}$ & $0,59^{\mathrm{b}}$ & $0,52^{\mathrm{b}}$ & $0,55^{\mathrm{b}}$ & $0,53^{\mathrm{b}}$ \\
\hline C18:1 Oleik asit & $33,92^{\mathrm{a}}$ & $28,15^{\mathrm{b}}$ & $27,91^{\mathrm{b}}$ & $28,33^{\mathrm{b}}$ & $28,21^{\mathrm{b}}$ & $27,96^{\mathrm{b}}$ & $28,36^{\mathrm{b}}$ \\
\hline$\sum$ MUFA & $31,2^{\mathrm{a}}$ & $30,59^{\mathrm{b}}$ & $29,92^{\mathrm{b}}$ & $29,53^{\mathrm{b}}$ & $30,1^{\mathrm{b}}$ & $30,6^{\mathrm{b}}$ & $30,2^{\mathrm{b}}$ \\
\hline \multicolumn{8}{|l|}{ PUFA } \\
\hline C18:2 ( $\omega-6)$ Linoleik asit & 10,42 & 10,56 & 10,43 & 10,26 & 10,33 & 10,59 & 10,12 \\
\hline $\mathrm{C} 18: 3(\omega-6)$ Linolenik asit & 2,95 & 2,86 & 2,22 & 2,36 & 2,27 & 2,11 & 2,33 \\
\hline C20:5 $(\omega-3)$ Eikosapentaenoikasit (EPA) & $3,41^{\mathrm{a}}$ & $2,52^{\mathrm{b}}$ & $2,26^{\mathrm{b}}$ & $2,33^{\mathrm{b}}$ & $2,41^{\mathrm{b}}$ & $2,27^{\mathrm{b}}$ & $2,41^{\mathrm{b}}$ \\
\hline C20:4 ( $\omega-6)$ Araşidonik asit & $1,33^{\mathrm{a}}$ & $1,06^{\mathrm{a}}$ & $1,01^{\mathrm{a}}$ & $0,93^{\mathrm{b}}$ & $0,96^{\mathrm{b}}$ & $0,81^{\mathrm{b}}$ & $0,88^{\mathrm{b}}$ \\
\hline C22:6 $(\omega-3)$ Dokosaheksanoik asit (DHA) & $9,17^{\mathrm{b}}$ & $11,26^{\mathrm{a}}$ & $10,93^{\mathrm{a}}$ & $8,73^{\mathrm{b}}$ & $7,51^{\mathrm{c}}$ & $7,96^{c}$ & $7,56^{\mathrm{c}}$ \\
\hline ¿PUFA & $27,3^{\mathrm{a}}$ & $25,16^{\mathrm{b}}$ & $25,11^{\mathrm{b}}$ & $24,93^{\mathrm{b}}$ & $24,51^{\mathrm{b}}$ & $24,33^{\mathrm{b}}$ & $24,11^{\mathrm{b}}$ \\
\hline$\sum$ UFA & $59,5^{\mathrm{a}}$ & $55,75^{\mathrm{b}}$ & $55,03^{\mathrm{b}}$ & $54,46^{\mathrm{b}}$ & $54.61^{\mathrm{b}}$ & $54,93^{\mathrm{b}}$ & $54,91^{\mathrm{b}}$ \\
\hline SFA/UFA & 0,54 & 0,57 & 0,57 & 0,58 & 0,59 & 0,57 & 0,55 \\
\hline
\end{tabular}

MÖ: Marinasyon öncesi, SFA: Doymuş yağ asitleri, UFA: Doymamış yağ asitleri, MUFA: Tekli doymamış yağ asitleri, PUFA: Çoklu doymamış yă̆ asitleri, a, b, c: Aynı satırda, farklı harfleri taşıyan ortalamalar arasında fark istatistik olarak önemlidir $(\mathrm{P}<0,05)$. 0: Marinasyon işleminin tamamlandığı ve filetoların paketlendiği gün

Marinasyon işlemi sonunda (0. ay) bu değerler M, B ve $K$ grubunda sirasiyla $0,72,0,70$ ve 0,61 ( $\%$ oleik asit cinsinden) tespit edilmiştir. Depolama boyunca SYA miktarları sürekli bir artış göstermiş, 3. ayın sonunda ise M grubu marinatların SYA'i 7,33 olarak ölçülmüş ve tüketilebilirlik sınır değerini aştığından ölçümlere devam edilmemiştir. $\mathrm{B}$ ve $\mathrm{K}$ gruplarında ise depolamanın başlangıcından itibaren 5 . ayın sonuna kadar sürekli bir artış gözlenmiş, 5. ayın sonunda SYA miktarı B ve K gruplarında sırası ile 3,82 ve 3,11 olarak kaydedilmiş ve iki grup arasındaki farkın istatistikî olarak önemsiz $(\mathrm{P}>0,05)$ olduğu ortaya konmuştur. Serdaroğlu ve 
Felekoğlu (2005), sardalya kıymasında biberiye yağı ve soğan suyunun oksidatif etkilerini araştırdıkları çalışmalarında; biberiye ilave edilen grubun serbest yă asidi miktarındaki artışının diğer iki gruba göre daha az oranlarda olduğunu saptamışlardır.

\section{Yă̆ Asidi Kompozisyonundaki Değişimler}

Taze alabalık örnekleri ile marine edilen örneklerin olgunlaştırma sonrası 1. gün ile depolama süresince periyodik olarak alınan numunelerin yağ asitleri analizlerinde metil esterleri temin edilebilen 12 adet yağ asidi araştırılmıştır. Elde edilen yağ asitleri bulguları Tablo 3' de verilmiştir.

Marinasyon teknolojisinde balıkta görülen en önemli değişimler proteinlerin yanı sıra yağlarda da meydana gelir. Ancak marinasyon teknolojisinin yağlara olan artı bir etkisi saptanamamıştır. Marine üründe yağlar, taze balık etinde olduğu gibi bir değişim göstermektedir. Özellikle yağlı balıklarda oksidatif ve hidrolitik acılaşma şeklinde bilinen bu değişimler, lezzet koku değişimi, asitlik değişimi, peroksit oluşumu, aldehit oluşumu ve keton oluşumu şeklinde sıralanabilir (Bakıcı, 1981).

Kontrol grubu örneklerinde, marinasyon öncesi alabalık filetolarının yağ asidi analizleri sonucunda toplam doymuş yă̆ asitleri içeriği \%32,41, toplam doymamış yağ asidi içeriği \%59,5 olarak bulunmuştur. Marinasyon işleminden önce filetolarda tespit edilen en yüksek değer \%33,92 ile oleik aside aittir. Marinasyon işlemi sonrasında, muhafaza periyodu boyunca oleik asit, araşidonik asit, EPA ve DHA değerlerinde düşüş şekillenmiş olup, istatistikî açıdan fark önemli bulunmuştur (Tablo 3). Biberiye ilave edilen gruba ait örneklerin yă̆ asidi değerleri incelendiğinde, kaproik, miristik ve palmitik asit miktarları marinasyon işleminden sonra artmıştır ve fark istatistiki açıdan önemli bulunmuştur $(\mathrm{P}<0,05)$. Toplam doymuş (SFA) ve doymamış yă (UFA) asitleri miktarlarında ise azalma meydana gelmiştir (Tablo 4). Kekik ilave edilen grupların yağ asidi bileşimi incelendiğinde marinasyon sonrası çoklu doymamış yağ asitlerinde azalış belirlenmiştir. Benzer şekilde EPA ve DHA miktarlarında da azalma tespit edilmiştir (Tablo 5).

Çetinkaya (2008), gümüş balığından elde ettiği marinatları 120 gün depolamış ve depolama boyunca, araşidonik asit, dokosahekzaenoik asit, linoleik asit, stearik asit, oleik asit, nispi bir artış, miristik asit, palmitik asit, palmitoleik asit ise nispi bir düşüş gözlemlemiştir. Bizim çalışmamızda ise araşidonik asit, dokosahekzaenoik asit, linoleik asit, oleik asit tüm gruplarda depolamanın sonunda düşüş, miristik asit ve palmitik asit $B$ ve $K$ gruplarında nispi bir artış $M$ grubunda ise nisbi düşüş göstermiştir. Palmitoleik asit $\mathrm{B}$ grubunda nispi bir artış, $M$ ve $K$ grubunda nispi düşüş, stearik asit ise $B$ grubunda sabit kalırken $M$ ve $K$ gruplarında nispi artış göstermiştir.

Sonuç olarak, doğal katkı maddesi olan biberiye ve kekik yağının muhafaza süresi boyunca kimyasal parametreleri nasıl etkilediği araştırılmış ve kontrol grubu örneklerine göre muhafazayı 2 ay daha uzattığg, kekik yağının biberiye yağına göre daha koruyucu olduğu ve beslenmemizde önemli olan yağ asitleri üzerine de her iki yağın olumsuz etkisinin olmadığı tespit edilmiştir.

Tablo 5 Kekik ekstraktı ilave edilen gruba (K grubu) ait örneklerin muhafazası sırasında tespit edilen yağ asidi değerleri Table 5 Fatty acid values detected during storage of fillet samples of thyme oil with group

\begin{tabular}{|c|c|c|c|c|c|c|c|}
\hline \multirow{2}{*}{ Yağ asitleri } & \multicolumn{6}{|c|}{ Muhafaza süresi (Ay) } & \multirow[b]{2}{*}{5} \\
\hline & MÖ & $0 *$ & 1 & 2 & 3 & 4 & \\
\hline \multicolumn{8}{|l|}{ SFA } \\
\hline C6:0 Kaproik asit & 0,04 & 0,06 & 0,08 & 0,11 & 0,09 & 0,10 & 0,11 \\
\hline C12:0 Laurik asit & 0,14 & 0,9 & 0,11 & 0,16 & 0,18 & 0,14 & 0,13 \\
\hline C14:0 Miristik asit & $3,81^{\mathrm{b}}$ & $3,7^{\mathrm{b}}$ & $3,64^{b}$ & $4,59^{\mathrm{a}}$ & $3,46^{\mathrm{b}}$ & $3,71^{\mathrm{b}}$ & $3,73^{\mathrm{b}}$ \\
\hline C16:0 Palmitik asit & $17,29^{\mathrm{b}}$ & $17,25^{\mathrm{b}}$ & $17,21^{\mathrm{b}}$ & $18,01^{\mathrm{ab}}$ & $19,06^{\mathrm{a}}$ & $18,23^{\mathrm{ab}}$ & $18,56^{\mathrm{ab}}$ \\
\hline C18: 0 Stearik asit & 5,53 & 5,49 & 5,31 & 5,52 & 5,61 & 5,63 & 5,59 \\
\hline$\sum$ SFA & $32,41^{\mathrm{a}}$ & $32,71^{\mathrm{a}}$ & $31,13^{\mathrm{ab}}$ & $32,56^{\mathrm{a}}$ & $31,27^{\mathrm{ab}}$ & $30,19^{\mathrm{b}}$ & $30,21^{b}$ \\
\hline \multicolumn{8}{|l|}{ UFA MUFA } \\
\hline C16:1 ( $\omega-6)$ Palmiteolik asit & $0,65^{\mathrm{a}}$ & $0,61^{\mathrm{a}}$ & $0,59^{\mathrm{b}}$ & $0,57^{\mathrm{b}}$ & $0,55^{\mathrm{b}}$ & $0,53^{\mathrm{b}}$ & $0,57^{\mathrm{b}}$ \\
\hline C18:1 Oleik asit & $33,92^{\mathrm{a}}$ & $27,56^{\mathrm{b}}$ & $27,13^{\mathrm{b}}$ & $27,16^{\mathrm{b}}$ & $27,41^{\mathrm{b}}$ & $27,21^{\mathrm{b}}$ & $27,33^{\mathrm{b}}$ \\
\hline$\sum$ MUFA & $31,2^{\mathrm{a}}$ & $29,51^{\mathrm{a}}$ & $28,7^{\mathrm{b}}$ & $28,13^{\mathrm{b}}$ & $29,6^{\mathrm{a}}$ & $29,7^{\mathrm{a}}$ & $28,9^{\mathrm{a}}$ \\
\hline \multicolumn{8}{|l|}{ PUFA } \\
\hline C18:2 ( $\omega-6)$ Linoleik asit & 10,42 & 10,33 & 10,21 & 10,42 & 10,19 & 10,26 & 10,14 \\
\hline $\mathrm{C} 18: 3(\omega-6)$ Linolenik asit & 2,95 & 2,53 & 2,49 & 2,11 & 2,03 & 2,19 & 2,21 \\
\hline C20:5 $(\omega-3)$ Eikosapentaenoikasit (EPA) & $3,41^{\mathrm{a}}$ & $2,11^{\mathrm{b}}$ & $1,80^{\mathrm{c}}$ & $1,83^{\mathrm{c}}$ & $1,79^{\mathrm{c}}$ & $1,66^{\mathrm{c}}$ & $1,58^{\mathrm{c}}$ \\
\hline $\mathrm{C} 20: 4(\omega-6)$ Araşidonik asit & $1,33^{\mathrm{a}}$ & $0,83^{\mathrm{b}}$ & $0,76^{\mathrm{b}}$ & $0,79^{\mathrm{b}}$ & $0,63^{\mathrm{c}}$ & $0,65^{\mathrm{c}}$ & $0,59^{c}$ \\
\hline C22:6 $(\omega-3)$ Dokosaheksanoikasit(DHA) & $9,17^{\mathrm{a}}$ & $10,99^{\mathrm{a}}$ & $9,56^{\mathrm{a}}$ & $9,23^{\mathrm{a}}$ & $8,31^{\mathrm{b}}$ & $8,26^{\mathrm{b}}$ & $8,28^{\mathrm{b}}$ \\
\hline ¿PUFA & $27,3^{\mathrm{a}}$ & $23,42^{\mathrm{b}}$ & $24,11^{\mathrm{b}}$ & $23,56^{\mathrm{b}}$ & $23,31^{\mathrm{b}}$ & $24,19^{b}$ & $24,11^{b}$ \\
\hline$\sum$ UFA & $59,5^{\mathrm{a}}$ & $52,93^{\mathrm{b}}$ & $52,81^{\mathrm{b}}$ & $51,69^{\mathrm{b}}$ & $52,91^{\mathrm{b}}$ & $53,89^{\mathrm{b}}$ & $53,73^{b}$ \\
\hline SFA/UFA & $0,54^{\mathrm{b}}$ & $0,61^{\mathrm{a}}$ & $0,58^{\mathrm{b}}$ & $0,62^{\mathrm{a}}$ & $0,59^{\mathrm{b}}$ & $0,56^{\mathrm{b}}$ & $0,51^{\mathrm{b}}$ \\
\hline
\end{tabular}

MÖ: Marinasyon öncesi, SFA: Doymuş yağ asitleri, UFA: Doymamış yağ asitleri, MUFA: Tekli doymamış yağ asitleri, PUFA: Çoklu doymamış yağ asitleri, a,b, c: Aynı satırda, farklı harfleri taşıyan ortalamalar arasında fark istatistik olarak önemlidir $(\mathrm{P}<0,05)$. 0: Marinasyon işleminin tamamlandığı ve filetoların paketlendiği gün 


\section{Teşekkür}

$\mathrm{Bu}$ çalışma yüksek lisans tezinden özetlenmiş olup, CÜ Bilimsel Araştırma Projeleri (CÜBAP) tarafından desteklenmiştir.

\section{Kaynaklar}

AOAS. 1994. Official Methods and Recommended Practices of the American Oil Chemists Society. American Oil Chemists Society, Champaign,IL.

Bakıc1 İ. 1981. İstavritlerde Soğuk Muhafaza Süresince Meydana Gelen Sensorial Değișiklikler (Uzmanlık Tezi). Ankara Üniversitesi, Veterinerlik Fakültesi, Ankara, Türkiye, $125 \mathrm{p}$.

Belitz HD, Grosch W. 1999. Lipids in. Belitz HD and Grosch W, Eds, Food Chemistry, 2nd,Berlin, Germany: SpringerVerla; $152-157$.

Cadun A, Kışla D, Çaklı Ş. 2008. Marination of Deep-Water Pink Shrimp with Rosemary Extract and the Determination of Its Shelf-Life, Food Chemistry, 109 (1): 81-87.

Connell JJ. 1980. Marinades, p.102-105. In Control of Fish Quality 2nd ed,Torry Research Station, Aberdeen, Scotland, ISBN 0-85238-105-0.

Çaklı Ş. 2007. Su Ürünleri İşlem Teknolojisi1, Ege Üniversitesi Yayınları, Su Ürünleri Fakültesi Yayın No:76. Bornova İzmir,Türkiye, 696 p.

Çetinkaya S. 2008. Eğirdir Gölü'nden Avlanan Gümüş Balığ (Atherina boyeri, Risso 1810)'ndan Marinat Yapımı ve Bazı Besinsel Özelliklerinin Tespiti, Yükseklisans Tezi, Süleyman Demirel Üniversitesi, Fen Bilimleri Enstitüsü,Isparta, $126 \mathrm{p}$.

Eke E. 2007. Farklı Balık Türlerinden Marinat Yapımı ve Kalitesinin Belirlenmesi,Yüksek Lisans Tezi, Ondokuz Mayıs Üniversitesi, Fen Bilimleri Enstitüsü, Samsun, 64s.

Gökoğlu N. 2002. Su Ürünleri İşleme Teknolojisi. Su Vakfi Yayınları, Antalya,115 s.

Gökoğlu N, Cengiz E, Yerlikaya, P. 2004. Determination of the Shelf Life of Marinated Sardine (Sardina pilchardus) Stored at $4{ }^{\circ} \mathrm{C}$, Food Control, 15: 1-4.
Nassu RT, Gonçalves LAG, Pereira da Silva MAA, Beserra FJ. 2003. Oxidativestability of Fermented Goat Meat Sausage With Different Levels Of Natural Antioxidant. Meat Sci, 63 (1): 43-49.

Olgunoğlu İA. 2007. Marine Edilmiş Hamside (Engraulis engrasicholus, L., 1758) Duyusal, Kimyasal ve Mikrobiyolojik Değişimler,Doktora Tezi, Çukurova Üniversitesi Fen Bilimleri Enstitüsü,Adana, $111 \mathrm{~s}$.

Önenç SS, Açıkgöz,Z. 2005. Aromatik Bitkilerin Hayvansal Ürünlerde Antioksidan Etkileri,Hayvansal Üretim, 46(1):5055 .

Özden Ö, Erkan N. 2006. Effect of Different Packing Methods On The Shelf Life Of Marinated Rainbow Trout, Archiv für Lebensmittelhygiene, 57: 69-75.

Özoğul Y, Kuley E, Özoğul F. 2009. Qality Changes of Marinated Tench (Tinca tinca) During Refrigerated Storage. Food Sci. Tech. İnt. 15(5): 513-521.

Serdaroğlu M, Felekoğlu E. 2005. Effect of Using Rosemary Extract and Onıon Juice on Oxidative Stability of Sardine (Sardina pilchardus) Mince. Journal of Food Quality 28: 109-120.

Sherwin ER. 1990. Food Additives. Ed. by L. Branen, Marcel Dekker, New York, pp. 139-193.

Spiller GA. 1996. Lipid in Human Nutrition Handbook, Mannuals, etc. CRS Press, İnc, 2000 Corporate Blvd, NW, Boca Raton, FL 33431, 1996; 54.

Tarladgis BG, Watts BM, Yonathan,M. 1960. Distillation Method for The Determination of Malonaldehyde in Rancid Foods. J. Of American Oil Chemistry Society, 44-48p.

Varlık C, Uğur M, Gökoğlu N, Gün H. 1993. Su Ürünlerinde Kalite Kontrol İlke ve Yöntemleri, Gıda Teknolojisi Derneği, Gıda Teknolojisi Yayın No: 17, Ankara Üniversitesi Ziraat Fakültesi, 173 p.

Yanishlieva NV, Marinova E, Pokorny J. 2006. Natural Antioxidants From Herbs and Spices Eur. Journal Lipid Science Technol, 108: 776-793.

Yapar A, Erdöl M. 1999. Buzdolabında Muhafaza Edilen Mezgit (Merlangius merlanguseuxinus nord.,1840) Karaciğer Yağının Bazı Özelliklerinde Meydana Gelen Değişmeler.Turk J Vet Anim Sci, 1999 (23: 333-336. 